\title{
Occlusal Characteristics of Deaf-Mute Individuals in the Turkish Population
}

\author{
Semra Cigera \\ Seden Akan ${ }^{b}$
}

\section{ABSTRACT}

Objectives: To classify and determine the occlusal characteristics of deaf-mute individuals and its gender distribution in the Turkish population.

Methods: For this study, 213 deaf-mute individuals (155 boys and 58 girls) were evaluated. The age range was between $10-24$ years, and the mean age was $16.37 \pm 2.53$ years. Measurements were divided into four groups: dental, intraarch, interarch, and, extra data.

Results: Of the participants, $75.0 \%$ had a Class I molar relationship, whereas $13.0 \%$ and $8.0 \%$ had Class II and Class III malocclusions, respectively. $23.9 \%$ of individuals had a normal overbite, $38.4 \%$ had a deepbite, and $23.4 \%$ had an openbite. One or more congenitally missing teeth were found in $6.0 \%$ of individuals; $81.0 \%$ expressed satisfaction with their esthetics, and $19.0 \%$ expressed the contrary.

Conclusions: Different characteristics and malocclusions are present in deaf-mute individuals. (Eur J Dent 2010;4:128-136)

Key words: Deaf mutism; Occlusal characteristics; Overbite; Openbite; Turkish population.

a Professor, Department of Orthodontics, Faculty of Dentistry, Hacettepe University, Ankara, Turkey.

b Research Assistant, Department of Orthodontics, Faculty of Dentistry, Hacettepe University, Ankara, Turkey.

- Corresponding author: Dt. Seden Akan, Hacettepe Universitesi, Dis Hekimligi Fakultesi, Ortodonti Anabilim Dali, Sihhiye, 06100 Ankara, Turkey. Phone: +905355113760

Fax: +903123091138

E-mail: sedenakandtahotmail.com

\section{INTRODUCTION}

Deaf mutism is a major health problem and limits appropriate communication and learning that is necessary for the normal development and maturation of a child. ' Its etiology is generally due to hearing lose before the age of $2-3$ years, which hinders the child being able to learn how to speak; congenital deaf mutism is also a possible etiology. Most cases of deaf mutism result from acute infectious diseases such as measles, epidemic 
meningitis, encephalitis, typhoid, otitis media, or toxic effects of drugs. ${ }^{2}$

Deaf-Mute Individuals (DMI) constitute one of the largest groups of disabled individuals. The World Health Organization (WHO) ${ }^{3}$ estimates that in 2001, 250 million people worldwide had a disabling hearing impairment (moderate or severe hearing impairment in the better ear). In Turkey, it is estimated that 500 children with hearing impairment are born each year; ${ }^{4}$ there were 158,000 deaf children in $1990 .{ }^{5}$ According to the Turkish Ministry of Education, ${ }^{6}$ there are currently 63 schools for the deaf in Turkey that enrolled a total number of 6,268 students for the 2007-2008 school year. The number of deaf-mute subjects who receive special education accounts for only approximately $5.46 \%$ of all deaf-mute subjects in Turkey.

Studies ${ }^{7,8}$ report that prelingually deafened subjects establish open articulatory postures with excessive jaw displacement and minimal tongue movement, and do not contract and extend their tongues as do hearing talkers. A change in tongue muscle function can either cause morphologic variations in the normal configuration of the teeth and supporting bone, or it can exacerbate an existing malocclusion. ${ }^{9}$

There are studies ${ }^{1-8,10}$ that have evaluated abnormalities in DMI in Turkey: Egeli et al ${ }^{1}$ found that, out of 162 cases of DMI, 7 individuals had jaw abnormalities and 11 had tooth abnormalities. Öztürk et al ${ }^{10}$ report 13 facial asymmetries, 3 cleft tongues, 2 cleft lips, 2 maxillary hypoplasias, 1 cleft palate, 1 prognatism, 11 long face, and 1 lobular tongue subject out of 840 deaf primary school children in Turkey. No study that examines occlusal characteristics of DMI in Turkish populations has been reported in the literature.

The aim of this study is to determine occlusal characteristics of deaf-mute individuals in the Turkish population.

\section{MATERIALS AND METHODS}

For this longitudinal study, 213 deaf-mute individuals - 155 boys (73.0\%) and 58 girls (27.0\%) - in the permanent dentition between the ages of 10 24 years who attend special needs schools in the city of Ankara were evaluated. The mean age of the individuals was $16.37 \pm 2.53$ years; none of the subjects had received orthodontic treatment before the study.

Measurements were recorded using the one recorder (SC) on the form (Figure 1) which was ap- proved by the Federal Dentaire International (FDI). This form was primarily for study purposes only. ${ }^{11}$ Measurements were divided into four groups and are shown in Table 1.

\section{Statistical method}

Data analysis was performed using the Statistical Package for Social Sciences (SPSS) version 11.5 software (SPSS Inc., Chicago, IL, United States). Pearson Chi-square tests were used to assess the statistical significance of gender differences in the frequency distribution of categorical variables, unless the expected cell size was less than five or ten, when Fisher's Exact test or Continuity Corrected Chi-square tests were used. Whether or not the differences between gender groups in the subsets of number of missing, malformed, impacted, and extracted teeth were statistically significant was evaluated by using the Mann Whitney $U$ test. A binomial test was applied in order to detect the differences in prevalence between male and female groups. A P value less than .05 was considered statistically significant.

\section{RESULTS}

The prevalence of male individuals in this study group was found to be statistically significant higher than girls $(P<.001)$.

\section{Interarch measurements}

Anteroposterior molar relationship

The molar relationship was evaluated as Class I, Class II, and Class III according to Angle classification. Subjects whose molar relationship could not be determined because of molar extractions and subjects with different molar relationships on the right and left sides were not classified. Table 2 shows that 160 subjects (75.0\%) had Class I malocclusions, 27 (13.0\%) had Class II, 18 (8.0\%) had Class III, and 8 (4.0\%) individuals were not classified.

\section{Vertical relationship}

In this research, a $2 \mathrm{~mm}$ overbite is accepted as normal, negative values are classified as an openbite, and more than $2 \mathrm{~mm}$ is classified as a deepbite. According to this classification system, $51(23.9 \%)$ DMI had a normal overbite, 82 (38.4\%) had a deepbite, and 50 (23.4\%) had an openbite. The distribution of overbite between genders is presented in Table 2; a statistically significant difference was found $(P<.05)$. 
According to the localization, openbite is divided into three groups: anterior, posterior, and anterior-posterior. According to this classification, $35(16.4 \%)$ DMI had anterior openbites, 9 $(4.2 \%)$ had posterior openbites, and $6(2.8 \%)$ had anterior-posterior openbites (Table 2). Based on the severity, openbite was evaluated in 3 groups; slight (1-2 $\mathrm{mm}$ ) openbite, moderate openbite (2-4 $\mathrm{mm}$ ), and severe openbite (more than $4 \mathrm{~mm}$ ).

According to this classification, $60(28.0 \%) \mathrm{DMI}$ had slight, $10(4.6 \%)$ had moderate, and $8(3.7 \%)$ had severe openbites (Table 2).
Transverse relationship

According to transverse relationship evaluation, $8(2.3 \%)$ individuals had a posterior crossbite, $6(1.9 \%)$ had a brodiebite (buccal nonocclusion) (Table 2).

Dental measurements

Congenitally missing teeth

In this group of DMI, congenitally missing teeth were found in 13 subjects $(6.0 \%)$, but none of the subjects had more than 3 congenitally missing teeth (Table 3). Most frequently, the missing teeth
RECORD FORM
Schaol:
No:
Name and Surnam
Birthday and Place:

Sex:

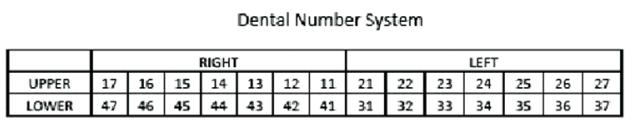

Dental Measurements

1-Develapment Anomalies:

a) Congenitally Missing Teeth:

b) Supernumeral Teeth:

c) Malfarmed Teeth

d) Impacted Teeth:

e) Transpazed Teeth:

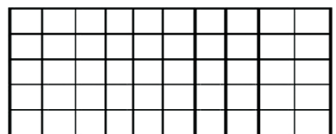

2-Teeth Extracted Because Of Trauma:

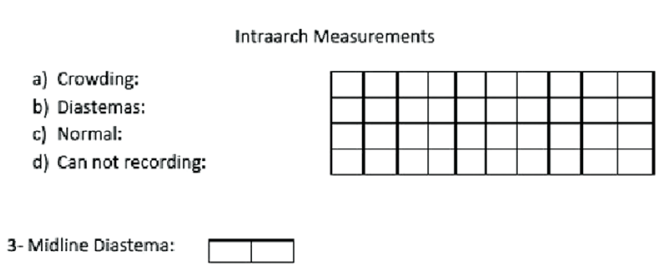

Midline Diastema:
Interarch Measurements

4-Lateral Segments:

a)Anteroposterior (Malar Relationship)

b) Vertically (Posterior Openbite)

c)Transverse (Posterior Crossbite)

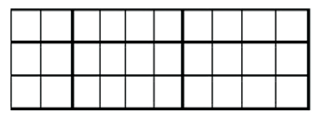

5- Anterior Segments:

a)Anteroposterior (Overjet)

b)Vertically (Openbite)

c)Transverse (Crassbite)

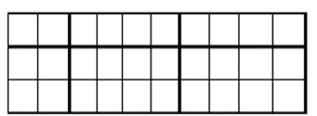

Extra Data

6- Oral Hygiene:

7. Pleasure of Esthetic:

8-Previous Orthodontic Treatment:

Figure 1. The form was used in the present study.

Table 1. Measurement groups.

\begin{tabular}{|c|c|c|c|}
\hline Interarch Measurements & Dental Measurements & Intraarch Measurements & Extra Data \\
\hline Anteroposterior molar relationship & Congenitally missing teeth & Diastemas & Muscle tone \\
\hline Vertical relationship & Supernumerary teeth & Crowding & Oral hygiene \\
\hline \multirow[t]{3}{*}{ Transverse relationship } & Malformed teeth & & $\begin{array}{c}\text { Esthetic } \\
\text { satisfaction }\end{array}$ \\
\hline & Impacted teeth & & \\
\hline & $\begin{array}{l}\text { Teeth extracted because of } \\
\text { trauma }\end{array}$ & & \\
\hline
\end{tabular}

European Journal of Dentistry 
were lateral maxillary incisors ( $n=11$; prevalence: $50.0 \%$; Table 4), or mandibular second premolars ( $n=6$; prevalence: $26.0 \%$; Table 4). There were no missing canines, first premolars, or first and second molars. No statistically significant gender difference was found regarding missing teeth.

\section{Supernumerary teeth}

No supernumerary teeth were found in this group of DMI.

\section{Malformed teeth}

In this group, 37 malformed teeth were seen in 16 individuals; its prevalence was $7.5 \%$. One male subject had 8 malformed teeth; this was the highest number of malformed teeth per subject in this group. Malformed teeth were found to be 6 times more frequent in boys than in girls (Table 3), but this difference was not statistically significant $(P=0.84)$. The most frequently malformed teeth were the maxillary lateral incisors $(n=16$; preva-

Table 2. Distributions of occlusal characteristics between genders (*: $\left.\mathrm{P}<.05,{ }^{* *}: \mathrm{P}<.01\right)$.

\begin{tabular}{|c|c|c|c|c|c|c|}
\hline & & Male & Female & Total & $\%$ & $\mathrm{P}$ \\
\hline \multirow{5}{*}{ Malocclusion } & $\mathrm{Cll}$ & 116 & 44 & 160 & 75 & 0.878 \\
\hline & $\mathrm{ClII}$ & 19 & 8 & 27 & 13 & 0.945 \\
\hline & Cl III & 14 & 4 & 18 & 8 & 0.785 \\
\hline & Not groupped & 6 & 2 & 8 & 4 & 1.000 \\
\hline & Total & 155 & 58 & 213 & 100 & \\
\hline \multirow{4}{*}{ Overbite } & normal & 32 & 19 & 51 & 23.9 & $0.035^{*}$ \\
\hline & deepbite & 67 & 15 & 82 & 38.4 & $0.028^{*}$ \\
\hline & openbite & 36 & 14 & 50 & 23.4 & 0.738 \\
\hline & Total & 135 & 48 & 183 & 85.9 & \\
\hline \multirow{4}{*}{ Openbite } & anterior openbite & 30 & 5 & 35 & 16.4 & 0.143 \\
\hline & posterior openbite & 5 & 4 & 9 & 4.2 & 0.065 \\
\hline & ant+post openbite & 5 & 1 & 6 & 2.8 & 1.000 \\
\hline & Total & 40 & 10 & 50 & 23.4 & \\
\hline \multirow{4}{*}{ Severity of openbite } & $1-2 \mathrm{~mm}$ & 51 & 9 & 60 & 28 & 0.483 \\
\hline & $2-4 \mathrm{~mm}$ & 8 & 2 & 10 & 4.6 & 0.670 \\
\hline & $4 \mathrm{~mm}-$ & 6 & 2 & 8 & 3.7 & 0.614 \\
\hline & Total & 65 & 13 & 78 & 36.6 & \\
\hline \multirow{4}{*}{ Transverse relationship } & normal & 110 & 38 & 148 & 69.4 & 0.208 \\
\hline & crossbite & 5 & 3 & 8 & 2.3 & 0.449 \\
\hline & brodiebite & 3 & 3 & 6 & 1.9 & 0.346 \\
\hline & Total & 118 & 44 & 162 & 76 & \\
\hline \multirow{4}{*}{ Crowding } & slight & 13 & 6 & 19 & 8.9 & 1.000 \\
\hline & moderate & 6 & 2 & 8 & 3.7 & 0.695 \\
\hline & severe & 10 & 7 & 17 & 18.3 & 0.645 \\
\hline & Total & 29 & 15 & 44 & 20.6 & \\
\hline
\end{tabular}


lence: $44.0 \%$; Table 4), followed by the maxillary and mandibular central incisors and maxillary second molars ( $\mathrm{n}=4$; prevalence: $11.0 \%$; Table 4).

\section{Impacted teeth}

In DMI, 22 impacted teeth were seen in 15 individuals; its prevalence was $7.0 \%$ (Table 3 ). The most frequently impacted teeth were maxillary canines ( $\mathrm{n}=20$; prevalence: $44.0 \%$; Table 4), followed by mandibular second premolars and canines ( $n=1$; prevalence: $4.5 \%$; Table 4). A statistically significant gender difference for impacted teeth was found $(P<.05)$

\section{Extracted teeth}

A total of 107 teeth were missing due to extraction in 52 male and 12 female DMI; the total prevalence was $30.0 \%$ (Table 3). The most frequently extracted teeth were mandibular first molars $(n=54$; prevalence: $51.0 \%$; Table 4), followed by maxillary first molars ( $n=36$; prevalence: $34.0 \%$; Table 4). Table 3 illustrates the fact that male individuals presented with extracted teeth approximately 4 times more frequently than females, although this difference was not statistically significant ( $P=0.05)$. No canine extraction was seen in this group.

Intraarch measurements

Diastemas and crowding

In DMI, 44 subjects (20.6\%) had crowding and $40(18.7 \%)$ had diastemas in their dental arches. There were 29 males and only 15 females who had crowding (Table 2). In this research, crowding was divided into three groups: slight $10-2 \mathrm{~mm}$ crowding in any dental arch), moderate (2-4 mm), and severe (more than $4 \mathrm{~mm}$ ). The distribution of subjects according to gender and severity of crowding is presented in Table 2.

\section{Extra data}

Oral hygiene

Of all the participants, 49 (30.0\%) DMI had good oral hygiene, 48 (29.0\%) had moderate hygiene, and $67(41.0 \%)$ had poor oral hygiene (Table 5). There were statistically significant differences be-

Table 3. Number and gender distribution of dental characteristics (*: $\mathrm{P}<.05,{ }^{* *}$ : $\mathrm{P}<.01$ ).

\begin{tabular}{|c|c|c|c|c|c|c|c|c|}
\hline & Per subject & Male & Female & $\begin{array}{l}\text { Subject } \\
\text { Number }\end{array}$ & $\%$ & Teeth Number & $\%$ & $P$ \\
\hline \multirow{4}{*}{ Missing teeth } & 1 & 3 & 2 & 5 & 2 & 5 & 23 & \multirow{4}{*}{0.349} \\
\hline & 2 & 5 & 2 & 7 & 3 & 14 & 63 & \\
\hline & 3 & 0 & 1 & 1 & 0.5 & 3 & 14 & \\
\hline & Total & 8 & 5 & 13 & 6 & 22 & 100 & \\
\hline \multirow{5}{*}{ Malformed teeth } & 1 & 4 & 1 & 5 & 2.3 & 5 & 13.5 & \multirow{5}{*}{0.840} \\
\hline & 2 & 5 & 3 & 8 & 3.7 & 16 & 43.3 & \\
\hline & 4 & 2 & - & 2 & 1 & 8 & 21.6 & \\
\hline & 8 & 1 & - & 1 & 0.5 & 8 & 21.6 & \\
\hline & Total & 12 & 2 & 16 & 7.5 & 37 & 100 & \\
\hline \multirow{3}{*}{ Impacted teeth } & 1 & 3 & 5 & 8 & 3.7 & 8 & 36 & \multirow{3}{*}{$0.021 *$} \\
\hline & 2 & 4 & 3 & 7 & 3.3 & 14 & 64 & \\
\hline & Total & 7 & 8 & 15 & 7 & 22 & 100 & \\
\hline \multirow{5}{*}{ Extracted teeth } & 1 & 26 & 9 & 35 & 16 & 35 & 33 & \multirow{5}{*}{0.050} \\
\hline & 2 & 18 & 1 & 19 & 9 & 38 & 35 & \\
\hline & 3 & 4 & 2 & 6 & 3 & 18 & 17 & \\
\hline & 4 & 4 & 0 & 4 & 4 & 16 & 15 & \\
\hline & Total & 52 & 12 & 64 & 30 & 107 & 100 & \\
\hline
\end{tabular}


Table 4. Distribution of dental characteristics for the jaw.

\begin{tabular}{|c|c|c|c|c|c|c|c|c|c|}
\hline & & \multicolumn{4}{|c|}{ Maxillary teeth } & \multicolumn{4}{|c|}{ Mandibular teeth } \\
\hline & & Right & Left & No & $\%$ & Right & Left & No & $\%$ \\
\hline \multirow{7}{*}{ Congenitally missing teeth } & Central incisor & 1 & 1 & 2 & 9 & 1 & 1 & 2 & 9 \\
\hline & Lateral incisor & 6 & 5 & 11 & 50 & & & & \\
\hline & Canine & & & & & & & & \\
\hline & First premolar & & & & & & & & \\
\hline & Second premolar & & 1 & 1 & 5 & 4 & 2 & 6 & 27 \\
\hline & First molar & & & & & & & & \\
\hline & Second molar & & & & & & & & \\
\hline \multirow{7}{*}{ Malformed teeth } & Central incisor & 2 & 2 & 4 & 11 & 2 & 2 & 4 & 11 \\
\hline & Lateral incisor & 8 & 8 & 16 & 44 & 1 & 1 & 2 & 5 \\
\hline & Canine & 1 & 1 & 2 & 5 & & & & \\
\hline & First premolar & 1 & 1 & 2 & 5 & 1 & & 1 & 3 \\
\hline & Second premolar & & & & & & & & \\
\hline & First molar & & & & & & & & \\
\hline & Second molar & 2 & 2 & 4 & 11 & 1 & 1 & 2 & 5 \\
\hline \multirow{7}{*}{ Impacted teeth } & Central incisor & & & & & & & & \\
\hline & Lateral incisor & & & & & & & & \\
\hline & Canine & 12 & 8 & 20 & 91 & 1 & & 1 & 4.5 \\
\hline & First premolar & & & & & & & & \\
\hline & Second premolar & & & & & 1 & & 1 & 4.5 \\
\hline & First molar & & & & & & & & \\
\hline & Second molar & & & & & & & & \\
\hline \multirow{7}{*}{ Extracted teeth } & Central incisor & 2 & 1 & 3 & 2.5 & & & & \\
\hline & Lateral incisor & & & & & 1 & & 1 & 1 \\
\hline & Canine & & & & & & & & \\
\hline & First premolar & & 1 & 1 & 1 & & & & \\
\hline & Second premolar & 2 & 4 & 6 & 5 & 2 & & 2 & 2 \\
\hline & First molar & 20 & 17 & 37 & 34 & 31 & 25 & 56 & 51 \\
\hline & Second molar & & & & & & 1 & 1 & 1 \\
\hline
\end{tabular}

Table 5. Distribution of additional data between genders (*: $\mathrm{P}<.05,{ }^{* *}: \mathrm{P}<.01$ ).

\begin{tabular}{|c|c|c|c|c|c|c|}
\hline & & Male & Female & Total & $\%$ & $P$ \\
\hline \multirow{4}{*}{ Oral hygiene } & Good & 26 & 23 & 49 & 30 & $\mathrm{P}<.001^{* *}$ \\
\hline & Moderate & 41 & 7 & 48 & 29 & $0.048^{*}$ \\
\hline & Poor & 56 & 11 & 67 & 41 & $0.035^{*}$ \\
\hline & Total & 123 & 41 & 164 & 100 & \\
\hline \multirow{3}{*}{ Pleasure of esthetic } & Yes & 58 & 22 & 80 & 81 & 0.386 \\
\hline & No & 16 & 3 & 19 & 19 & 0.386 \\
\hline & Total & 74 & 25 & 99 & 100 & \\
\hline
\end{tabular}


tween genders who had good $(P<.001)$, moderate $(P<.05)$, and poor oral hygiene $(P<.05)$.

\section{Esthetic satisfaction}

Table 5 shows that 80 (81.0\%) DMI were satisfied with their esthetics, whereas $19(19.0 \%)$ were not.

\section{DISCUSSION}

Teeth are positioned in equilibrium, in the dental arch between the opposing forces of the lips and tongue. However, additional forces or tonus changes applied to the teeth over extended periods of time will upset the alignment of the dental arch, creating a malocclusion. ${ }^{9}$

There is research proposing that prelingually deafened talkers do not displace the tongue in order to establish vowel steady-state postures and excessively displace the jaw, and that deaf subjects appear to have a less flexible tongue during speech production than do hearing subjects. ${ }^{8}$ Considering this difference, the present study evaluates the occlusal characteristics of deaf-mute individuals in the city of Ankara.

Because the study group contains students from various parts of Anatolia, it is assumed to be a good representation of the Turkish population.

Because of the large and widely scattered sample group, we used malocclusion record forms approved by the FDI for this study. This form was initially used for normal individuals in a study ${ }^{11}$ and we used it as an opportunity to compare those results with our own.

Interarch and intraarch measurements are evaluated separately because malocclusions have different features ${ }^{11}$ which do not permit grouping.

The prevalence of different types of malocclusions may show great variability even in a population of the same origin; Thilander et $\mathrm{a}^{12}$ reports that malocclusion prevalence varies from 39.0\% to $93.0 \%$. According to our results, $75.0 \%$ of subjects had a Class I molar relationship, $13.0 \%$ had a Class II, 8.0\% had a Class III malocclusion, and $4.0 \%$ could not be grouped because of molar extractions and different molar relationships on the right and left sides.

There are several researches that examine the orthodontic needs of the population and the response of several different orthodontic treatment centers to this need. ${ }^{10-24}$ Güray et al, ${ }^{13}$ using the Treatment Priority Index (TPI), reports that $72.3 \%$ of 483 primary school students were in need of orthodontic treatment. Ugur et $\mathrm{al}^{14}$ studied 483 high society primary school students, also using TPI, and found that $40.3 \%$ had normal occlusions, $21.5 \%$ had slight malocclusions, $25.2 \%$ had malocclusions that required treatment, and $5.0 \%$ had severe malocclusions. Sarı et al ${ }^{15}$ evaluated 1602 patients that had accepted treatment and reports that $61.7 \%$ of patients had Class I; $25.1 \%$ had Class II, division $1 ; 3.0 \%$ had Class II, division 2; and $10.2 \%$ had Class III malocclusions. Sayın and Turkkahraman ${ }^{16}$ evaluated 1356 untreated patients and report that $64.0 \%$ patients had Class I, 24.0\% had Class II, and $12.0 \%$ had Class III malocclusions. Aytan ${ }^{11}$ used the same measurement method and evaluated the occlusal features of 1510 high school students. He reports that $56.4 \%$ had Class I, 6.9\% had Class II, 3.5\% had Class III molar relationships, and $33.0 \%$ could not be grouped. No significant differences were observed between the prevalence of malocclusions our study and those in previous studies that investigated Turkish, or other populations. In all, Class I malocclusions were found to be the most frequent malocclusion and Class III was the least frequent. Variant results may be explained primarily by sampling technique, local environmental influences (trauma, mouth breathing, or sucking habits), and nutrition.

Previous research ${ }^{10-27}$ has also evaluated the prevalence of malocclusions in different populations. Jones ${ }^{17}$ reports $53.8 \%$ Class I malocclusions, $33.2 \%$ Class II, and $12.9 \%$ Class III malocclusions in a Saudi Arabian population comprised of 132 subjects. Helm ${ }^{18}$ investigated Danish population in groups of 1700 subjects and found $14.0 \%$ normal occlusion, $58.0 \%$ Class I, 18.8\% Class II div 1, 2.7\% Class II div 2 and 4.0\% Class III malocclusion. Lew et al ${ }^{19}$ examined 1,050 Chinese subjects and reported that $7.1 \%$ had normal occlusions; $58.8 \%$ had Class I malocclusions; $18.8 \%$ had Class II, div $1 ; 2.7 \%$ had Class II, div 2; and $12.6 \%$ had Class III malocclusions.

There is no difference between normal individuals' results and the results of the present study except regarding congenital missing teeth. In the deaf-mute group, $6.0 \%$ of individuals had congenitally missing teeth, whereas $2.6 \%$ had missing teeth in the normal high school group. This differ- 
ence is most likely due to hereditary factors, but no study has been done to investigate the association between deafness and congenitally absent teeth.

In a study ${ }^{20}$ evaluating the prevalence of congenitally missing teeth in the Turkish population, it was reported that $20.6 \%$ of 3,043 people had missing teeth. Similar to our study, it was found that the most frequently missing teeth were maxillary lateral incisors, followed by mandibular second premolars.

According to intraarch measurements of our study, $20.6 \%$ individuals had crowding and $18.7 \%$ had diastema; in Aytan's study ${ }^{11}$ these values were $92.0 \%$ and $5.6 \%$, respectively. We consider that there are many congenitally missing teeth in the deaf-mute group; it appears that this reflects other intraarch measurements as well. Thus, the incidences of missing teeth and diastemas were high compared to that of crowding in the deafmute group. However, this is the first study that has evaluated a correlation between these variables.

In interarch measurements, the rates of deepbites and posterior crossbites were high in DMI, who appear to have a less flexible tongue during speech production than do hearing subjects. ${ }^{8}$ This difference could disrupt tongue function just as abnormal habits would. With changes in the tongue, cheek, and lip muscle functions, the overall effect is a significant narrowing of the maxillary arch, similar to that of open mouth syndrome or mouth breathing subjects. ${ }^{28,29}$ Because the tongue cannot exert the necessary pressure on the incisor segment, deepbites and crossbites may occur. ${ }^{9}$

According to additional data, twice as many DMI subjects exercise good oral hygiene compared to the normal group. ${ }^{11}$ This shows that on average, $\mathrm{DMI}$ are more conscious of their oral hygiene than normal persons. When esthetic satisfaction was evaluated, $81.0 \%$ of DMI were satisfied with their appearance, compared to $73.0 \%{ }^{11}$ of normal individuals.

Al-Sarheed et $\mathrm{al}^{30}$ evaluated the parents of 77 visually impaired, 210 hearing impaired, and 494 control children, and finds that $56.7 \%$ of the hearing impaired group needed orthodontic treatment, compared to $55.0 \%$ in the control group. The authors further report that only $17.9 \%$ of parents of hearing impaired children believe that their children are not concerned about their dental ap- pearance. We believe that the high rate $(81.0 \%)$ of satisfaction in our study group indicates that the subjects are not overly concerned with their dental appearance.

\section{CONCLUSIONS}

In this study of deaf-mute individuals, the most common occlusal relationship was Class I, and the least common was Class III. We also found that the percentage of congenitally missing teeth, deepbites, posterior crossbites, and diastemas are higher in this population, whereas and the incidence of crowding is lower than that of normal individuals. Finally, oral hygiene and esthetic satisfaction rates are very high in deaf-mute individuals.

\section{REFERENCES}

1. Egeli E, Cicekci G, Silan F, Ozturk O, Harputluoglu U, Onur A, Egeli A, Yildiz A. Etiology of deafness at the Yeditepe School for the deaf in Istanbul. Int J Pediatr Otorhinolaryngol 2003;67:467-471.

2. Janzen VD, Schafer D. Etiology of deafness in Robarts School for the deaf. J Otolaryngol 1984;13:47-48.

3. WHO, WHO calls on private sector to provide affordable hearing aids in developing world, WHO/34, 11 July, 2001.

4. Belgin E, Akdas F, Boke B, Cağlar A. The children population with sensorineural hearing loss in Turkey. International meeting in Auditory for the Mediterranean Countries, 1991, p. 181.

5. 1. Specific Education Council: Guide Handbook of specific education institutions, Ministry of Education pres, Ankara, 1991; pp. 12-13.

6. National Education Statistics Formal Education 20072008. Ministry of National Education Strategy Development Presidency. A publication of official statistics programme. pp.26. http://sgb.meb.gov.tr

7. Obserger MJ. Training effects on vowel production by two profoundly hearing-impaired speakers. J Speech Hear Res 1987;30:241-251.

8. Tye-Murray N. The establishment of open articulatory postures by deaf-mute and hearing talkers. J Speech Hear Res 1991;34:453-459.

9. Graber TM. The "three M's": Muscles, malformation and malocclusion. Am J Orthod 1963;49:418-450.

10. Ozturk O, Silan F, Oghan F, Egeli E, Belli S, Tokmak A, Egeli A, Harputluoglu U, Onder HI, Zafer C. Evaluation of deaf children in a large series in Turkey. Int J Pediatr Otorhinolaryngol 2005;69:367-373.

11. Aytan S. Ankara ili ve çevresi lise öḡrencilerinde oklüzal özellikler. Hacettepe University, Ankara, Turkey-1978. Thesis. 
12. Thilander B, Pena L, Infante C, Parada SS, de Mayorga C. Prevalence of malocclusion and orthodontic treatment need in children and adolescents in Bogota, Colombia. An epidemiological study related to different stages of dental development. Eur J Orthod 2001;23:153-167.

13. Güray E, Orhan M, Ertaș E, Doruk C. Konya yöresi ilkokul çocuklarında Treatment Priority Index (TPI) uygulaması (epidemiyolojik çalıșma). Türk Ortodonti Dergisi 1994;7:195200.

14. Ū̄ur T, Cī̄er S, Aksoy A, Telli AE. An epidemiological survey using the Treatment Priority Index(TPI). Eur J Orthod 1998;20:189-193.

15. Sari Z, Uysal T, Karaman Al, Basciftci FA, Usumez S, Demir A. Orthodontic malocclusions and evaluation of treatment alternatives: an epidemiologic study. Turkish J Orthod 2003;16:119-126.

16. Sayin MO, Turkkahraman H. Malocclusion and crowding in an orthodontically referred Turkish population. Angle Orthod 2004;74.635-639.

17. Jones WB. Malocclusion and facial types in a group of Saudi Arabian patients referred for orthodontic treatment: a preliminary study. Br J Orthod 1987;14:143-146.

18. Helm S. Malocclusion in Danish children with adolescent dentition: an epidemiologic study. Am J Orthod 1968;54:352366.

19. Lew KK, Foong WC, Loh E. Malocclusion prevalence in an ethnic Chinese population. Aust Dent J 1993;38:442-449.

20. Altug-Atac AT, Erdem D. Prevalence and distribution of dental anomalies in orthodontic patients. Am J Orthod Dentofacial Orthop 2007;131:510-514.

21. Järvinen S. Indexes for orthodontic treatment need. Am J Orthod Dentofacial Orthop 2001;120:237-239.

22. Harrison RL, Davis DW. Dental malocclusion in native children of British Columbia, Canada. Community Dent Oral Epidemiol 1996;24:217-221.

23. Ng'ang'a PM, Ohito F, Ogaard B, Valderhaug J. The prevalence of malocclusion in 15 year-old children in Nairobi, Kenya. Acta Odontol Scand 1996;54:126-130.

24. Lauc T. Orofacial analysis on the Adriatic islands: an epidemiological study of malocclusions on Hvar Island. Eur J Orthod 2003;25:273-278.

25. Silva RG, Kang DS. Prevalence of malocclusion among Latino adolescents. Am J Orthod Dentofacial Orthop $2001 ; 119: 313-315$.

26. Diagne F, Ba I, Ba-Diop K, Yam AA, Ba-Tamba A. Prevalence of malocclusion in Senegal. Community Dent Oral Epidemiol 1993;21:325-326.

27. Liepa A, Urtane I, Richmond S, Dunstan F. Orthodontic treatment need in Latvia. Eur J Orthod 2003;25:279-284.

28. Aznar T, Galan AF, Marin I, Dominguez A. Dental arch diameters and relationships to oral habits. Angle Orthod 2006;76:441-445.
29. Gross AM, Kellum GD, Franz D, Michaz K, Walker M, Foster M, Bishop W. A longitudinal evaluation of open mouth posture and maxillary arch width in children. Angle Orthod 1994;64:419-424.

30. Al-Sarheed M, Bedi R, Hunt NP; The views and attitudes of parents of children with a sensory impairment towards orthodontic care. Eur J Orthod 2004;26:87-91. 